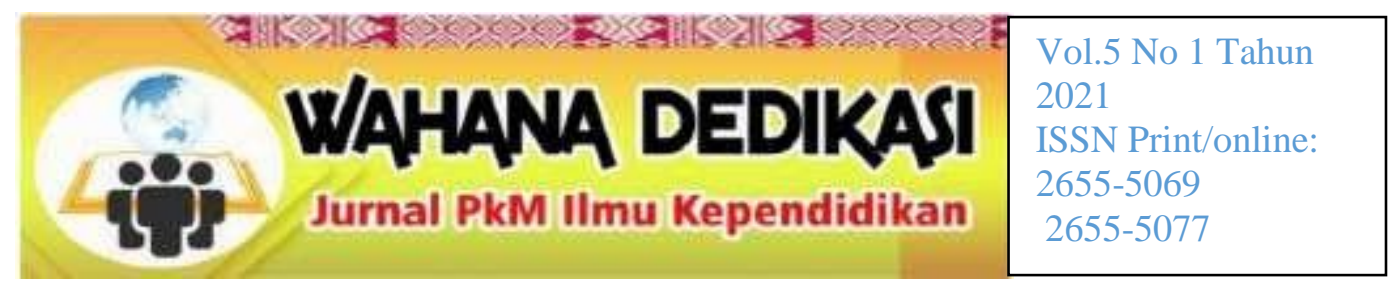

\title{
SOSIALISASI PEMAHAMAN ATAS PAJAK BEA \\ PEROLEHAN HAK ATAS TANAH BANGUNAN (BPHTB) BAGI MASYARAKAT KERINJING
}

\author{
Ermadiani $^{1}$, Rina Tjandrakirana ${ }^{2}$, Ika Sasti Ferina ${ }^{3}$, Eka Meirawati $^{4}$ \\ Program Studi Akuntansi Universitas Sriwijaya ${ }^{l, 2,3,4}$ \\ ermadiani@yahoo.co.id ${ }^{1}$,rinatjandrakirana@yahoo.com ${ }^{2}$, ikasastiferina10@gmail.com ${ }^{3}$, \\ e.meirawati@yahoo.com ${ }^{4}$
}

\begin{abstract}
Abstrak
Kegiatan yang dilaksanakan di desa Kerinjing Kabupaten Ogan Ilir Sumatera Selatan ini ditujukan untuk penduduk desa yang tercatat sebagai Wajib Pajak yang memperoleh hak atas tanah dan/atau bangunan. Permasalahan utama objek sasaran adalah kurangnya informasi,pemahaman, kesadaran dan kepatuhan dalam membayar BPHTB. Sosialisasi BPHTB sangat penting dilaksanakan mengingat sistem self-assessment yang dianut di Indonesia. Sistem ini menuntut wajib pajak memahami, memiliki kesadaran, kejujuran, keinginan dan kemampuan untuk menghitung, melaporkan dan membayar pajaknya sendiri (Undang-Undang Nomor 20 Tahun 2000 pasal 10 Ayat 1). Tujuan kegiatan ini agar penduduk desa Kerinjing Kabupaten Ogan Ilir Sumatera Selatan memahami penerapan Pajak BPHTB, menguasai regulasi terkait pemahaman dan kesadaran pembayaran Pajak BPHTB, memahami serta mengetahui informasi mengenai Pajak BPHTB. Kegiatan ini dilakukan dengan cara memberikan pemahaman terhadap penerapan Pajak BPHTB, kesiapan penguasaan regulasi terkait pemahaman dan kesadaran pembayaran Pajak BPHTB, serta kesiapan memahami dan memberikan informasi Pajak BPHTB bagi penduduk desa Kerinjing.

Kata kunci: Sosialisasi, Pemahaman, Pajak BPHTB
\end{abstract}

\begin{abstract}
This activity, which was carried out in the village of Kerinjing, Ogan Ilir Regency, South Sumatra, was aimed at villagers who were registered as taxpayers who obtained land and/or building rights. The main problem of the target object is the lack of information, understanding, awareness and compliance in paying BPHTB. The socialization of BPHTB is very important considering the selfassessment system adopted in Indonesia. This system requires taxpayers to understand, have awareness, honesty, desire and ability to calculate, report and pay their own taxes (Undang-Undang Number 20 Year 2000 Article 10 Paragraph 1 ). The purpose of this activity is so that the residents of Kerinjing village, Ogan Ilir Regency, South Sumatra understand the application of BPHTB Taxes, master regulations related to understanding and awareness of BPHTB Tax payments, understand and know information about BPHTB Taxes. This activity is carried out by providing an understanding of the application of BPHTB Taxes, readiness to master regulations related to understanding and awareness of BPHTB Tax
\end{abstract}




\section{WAHANA DEDIKASI}

payments, as well as readiness to understand and provide information on BPHTB Taxes for residents of Kerinjing Village.

Keywords: Socialization, Understanding, ВРHTB Tax.

Artikel Diterima : 26-11-2021Artikel disetujui tanggal:10-01-2022 Artikel Diterbitkan : 16-01-2022

Corresponden Author:Ermadiani e-mail:ermadiani@yahoo.co.id

DOI: http://dx.doi.org/10.31851/dedikasi.v5i1.6684 d

\section{PENDAHULUAN}

Pajak merupakan penerimaan negara yang paling tinggi jika dibandingkan penerimaan negara bukan pajak dan hibah. Berdasarkan data realisasi APBN 2020 pada kuartal pertama penerimaan pajak mencapai 711 triliun, sementara penerimaan negara bukan pajak hanya 208,8 triliun dan hibah sebesar 371,8 triliun. Oleh karena itu, pajak memegang peranan penting dalam perekonomian Indonesia sehingga pemerintah terus melakukan reformasi perpajakan. Dalam melaksanakan reformasi perpajakan, pemerintah melalukannya secara bertahap sehingga masyarakat bisa beradaptasi dan menghindari terjadinya ketidakpatuhan wajib pajak (Fujihana, 2010). Reformasi perpajakan dilakukan untuk memaksimalkan penerimaan pajak yang menjadi tombak bagi negara, salah satunya dalam pelaksanaan desentralisasi fiskal yang diatur pada tahun 2001.

Melalui desentralisasi fiskal, pemerintah daerah diberikan wewenang dari pemerintah pusat untuk mengelola sumber-sumber penerimaan dengan harapan meratanya pembanguann di setiap daerah. Kebijakan ini juga membangun hubungan di antara pemerintah pusat dan pemerintah daerah lebih ideal karena memberikan kewenangan kepada pemerintah daerah sehingga pembagunan nasional lebih efisien (Kertopati, 2015). Salah satu sumber pajak yang berpotensi digali oleh pemerintah daerah saat ini adalah Pajak Bea Perolehan Hak Atas Tanah dan Bangunan (BPHTB) karena sesuai dengan kondisi perekonomian Indonesia (Siahan, 2003).

Bea perolehan hak atas tanah dan bagunan (BPHTB) adalah pajak kebendaan terhadap objek pajak baru yang kemudian memperhatikan siapa yang menjadi subjek pajak tersebut (Resmi, 2017). Dalam pemungutannya, BPHTB diatur dalam Undang-Undang Nomor 20 Tahun 2000 pasal 10 Ayat (1) yang memberlakukan self assessment, yaitu wajib pajak diberikan kepercayaan untuk menghitung dan membayar sendiri pajak yang tertutang. Namun. pelaksanaan self assessment memiliki kelemahan karena kejujuran Wajib Pajak masih rendah, sehingga tidak mudah bagi petugas pemungut pajak untuk melakukan pemeriksaan pajak BPHTB yang terhutang. Diperlukannya sosialisasi kepada masyarakat agar hakikat self assessment dapat kembali sesuai tujuannya. Pada hakikatnya, self assessment bertujuan agar wajib pajak memiliki nilai-nilai kuat seperti kesadaran, kejujuran, disiplin, dan memiliki keinginan untuk membayar pajak (Mauludiah, 2015). Kesadaran membayar BPHTB di tengah 


\section{W/AHANA DEDIKASI}

masyarakat juga penting untuk dilaksanakaan karena warisan yang biasa timbul dari orang meninggal dunia dan hartanya diwariskan kepada orang lain memiliki kewajiban untuk mengurus proses peralihan hak atas tanah.

Kesadaran masyarakat untuk membayar pajak sudah patuh namun ada sebagian wajib pajak yang masih melalaikan kewajibannya sehingga target penerimaan ada yang belum terealisasi. Keadaan ini dapat kita lihat dari data target dan penerimaan BPHTB di kabupaten Ogan Ilir periode tahun 2015 sampai dengan 2019, pada tahun 2015 realisasi penerimaan PBB sebesar $3 \%$ dan mengalami kenaikan pada tahun 2016 sebesar $34 \%$, sedangkan pada tahun 2017 realisasi mengalami penurunan dengan realisasi sebesar $3 \%$. Namun, realisasi tahun 2018 dan 2019 mengalami kenaikan realisasi dari target anggaran sebesar $12 \%$ dan $68 \%$, sedangkan target penerimaan atas BPHTB semakin turun hingga tahun 2019, sehingga penurunan target BPHTB tahun 2018 dan 2019 turut mendorong partisipasi Pengabdian kepada masyarakat perguruan tinggi di Kabupaten Ogan Ilir khususnya sosialisasi kesadaran dan kepatuhan pembayaran BPHTB di daerah ini. Data rinci target dan realisasi BPHTB di kabupaten Ogan Ilir periode tahun 2015 sampai dengan 2019 dapat dilihat pada tabel 1.1 dibawah ini :

\section{Tabel 1.1 Target dan Penerimaan BPHTB Kabupaten Ogan Ilir periode 2015 s.d 2019}

\begin{tabular}{|c|c|c|c|}
\hline BPATB & Taget & Aagkasi & $\begin{array}{l}\text { Pessetas } \\
\text { Peretinan }\end{array}$ \\
\hline thaning & $590940 \% 7$ & 239110324 & is \\
\hline Tha:2018 & 148435639453 & $5 \mathrm{~m} 28 x$ & $x_{5}$ \\
\hline Then 217 & 3668343358 & $23 \mathrm{k} 540 \mathrm{0}$ & $x$ \\
\hline Istazois & $x+7050000$ & $2 \cos 60 x$ & 128 \\
\hline Iysez:219 & Thostuast & cosentegs & jex \\
\hline
\end{tabular}

Keadaan ini sangat penting karena sewaktu tanah tersebut dialihkan kepada pewaris maka harus membayar pajak BPHTB. Namun, sering kali ahli waris tidak segera atau justru mengabaikan proses peralihan hak atas tanah ini (Prastikaningtyas dan Permadi, 2014). Tentunya, hal ini berpengaruh terhadap sumber pendapatan yang diterima oleh pemerintah daerah. Oleh karena itu, pengabian ini akan membahas mengenai Pentingnya Sosialisasi Pemahaman Pajak Bea Perolehan Hak Atas Tanah dan Bangunan di Masyarakat.

Berdasarkan hal tersebut diatas berkaitan dengan kesadaran masyarakat atas kewajiban membayar pajak Bea Perolehan Hak atas Tanah dan Bangunan (BPHTB) di Kabupaten Ogan Ilir khususnya di Desa Kerinjing, sehingga perlu dilakukan sosialisasi kesadaran masyarakat atas kewajiban membayar pajak BPHTB.

Desa Kerinjing merupakan salah satu dari 241 desa yang ada diwilayah Kabupaten Ogan Ilir dan salah satu dari 19 Desa di wilayah Kecamatan Tanjung Raja yang terletak $7 \mathrm{Km}$ ke arah Barat dari Ibu Kota Kecamatan dan $13 \mathrm{Km}$ kearah Timur dari Ibu Kota Kabupaten dan 


\section{WAHANA DEDIKASI}

mempunyai luas $\pm 3,00 \quad \mathrm{Km}^{2}$. Desa Kerinjing terbagi

menjadi 2 dusun yang dipimpin oleh masing-masing Kepala Dusun. Adapun batas-batas wilayah Desa Kerinjing adalah sebagai berikut : Sebelah Utara berbatasan dengan Desa Jagaraja (Kec. Rantau Panjang), Sebelah Selatan berbatasan dengan Desa Tg Dayang (Kec. Indralaya Sel), Sebelah Barat berbatasan dengan Desa Suka Raja Baru, Suka Raja Lama, Sebelah Timur berbatasan dengan Skonjing.

Desa Kerinjing merupakan desa yang tertua nomor tiga diwilayah Kecamatan Tanjung Raja setelah Tanjung Raja dan Talang Balai. Sejak tanggal 12 Nopember 2006 Desa Kerinjing terjadi pemekaran menjadi 2 desa yaitu Desa Kerinjing dan Desa Skonjing. Hari jadi desa Skonjing jatuh pada tanggal 14 Februari 1856.

Desa Kerinjing memiliki jumlah penduduk pada akhir tahun 2020 sebanyak 1.350 jiwa, terdiri dari 685 laki-laki dan 665 perempuan (kepala desa, 2020). Pada akhir tahun 2020 jumlah rumah tangga sebanyak 470 Kepala Keluarga, dengan luas wilayah 3,00 km2 dan tingkat kepadatan penduduk rata-rata 426 jiwa per $\mathrm{km} 2$, merupakan desa dengan tingkat kepadatan penduduk relatif jarang (BPS 2016). Desa Kerinjing mempunyai Iklim kemarau dan penghujan sebagaimana desadesa lain diwilayah Indonesia dalam hal tersebut mempunyai pengaruh langsung terhadap pola tanam yang ada di desa Kerinjing Kecamatan Tanjung Raja.

Potensi yang ada didesa Kerinjing tidaklah cukup banyak tetapi mudah-mudahan dengan sentuhan bantuan dari pihak yang terkait, potensi desa tersebut dapat dikembangkan terutama dibidang pertanian dan perkebunan. Sebanyak $49 \%$ penduduk desa berpendapatan dari hasil pertanian dan perkebunan, lahan persawahan dengan luas \pm 84 $\mathrm{Ha}$ dan lahan perkebunan seluas $\pm 105 \mathrm{Ha}$ yang dapat dijadikan aspirasi pemerintah untuk membantu para petani dalam meningkatkan produktifitas hasil pertanian dengan didukung sarana dan prasarana yang memadai. Potensi didesa dibidang kesehatan seperti POSKESDES, POSYANDU dan BIDES, dari potensi ini memang sangatlah dibutuhkan masyarakat yang maju menuju Ogan Ilir sehat. Dari bidang ekonomi potensi desa juga dapat diliha dari usaha-usaha keluarga seperti pembuatan pakaian (penjahit), usaha angkutan umum, warungwarung sembako, sedangkan potensi dibidang sarana dan prasarana seperti jalan desa yang cukup panjang, sarana pendidikan. Potensi perikanan yang ada didesa Kerinjing cuma nelayan penangkap ikan sawah liar dan sebagian membudidayakan ikan air tawar, dibidang SDM masih banyak SDM yang terampil tetapi tidak bisa menggunakan keahliannya pada umum karena tidak didukung dengan pendidikan keterampilan yang memadai dan persaingan kerja yang banyak. Selain sektor pertanian dan perikanan di desa Kerinjing, Potensi bidang ekonomi potensi desa dapat dilihat dari usaha-usaha keluarga seperti pembuatan pakaian (penjahit), usaha angkutan umum, warungwarung sembako, dan Usaha 


\section{WAHANA DEDIKASI}

Ekonomi Mikro Kecil dan Menengah berjumlah 50 (kepala desa,2021). Potensi yang ada di Desa Kerinjing tersebut dapat dikembangkan dan juga memberikan peluang bagi pemerintah untuk mengoptimalkan penerimaan pajak dari Pajak BPHTB. Oleh karena itu, dibutuhkan sosialisasi agar tingkat pemahaman, kesadaran dan kepatuhan terhadap pembayaran Pajak BPHTB semakin meningkat. Sosialisasi BPHTB sangat penting dilaksanakan mengingat sistem selfassessment yang dianut di Indonesia. Sistem ini menuntut wajib pajak memahami, memiliki kesadaran, kejujuran, keinginan dan kemampuan untuk menghitung, melaporkan dan membayar pajaknya sendiri. Namun, penerapan kebijakan ini kemudian menjadi permasalahan baru yang dihadapi masyarakat yang berada di daerah yang belum begitu maju contohnya di Desa Kerinjing Kabupaten Ogan Ilir. Mereka belum memahami dan memiliki kesadaran dalam kewajiban pembayaran BPHTB.

Permasalahan utama objek
adalah kurangnya
sasaran kesadaran dan
informasi,pemahaman, kesam
kepatuhan dalam membayar BPHTB.
Pelaksanaan dalam proposal ini
adalah berupa sosialisasi dan
pemahaman pembayaran BPHTB
serta meningkatnya kesadaran dan
kepatuhan terhadap Pajak BPHTB.
Pendampingan berkelanjutan juga
diperlukan untuk memberikan
pemahaman lebih lanjut dan
konsistensi kepatuhan dalam
melaksanakan
perpajakannya.

Adapun tujuan khusus kegiatan pelaksanaan sosilasasi mengenai Pajak BPHTB bagi masyarakat desa antara lain :

a. Persiapan penduduk desa memahami penerapan Pajak BPHTB.

b. Kesiapan sumberdaya manusia dalam hal ini penduduk desa yang dikenakan Pajak BPHTB dari sisi kualitas penguasaan regulasi terkait pemahaman dan kesadaran pembayaran Pajak BPHTB.

\section{BAHAN DAN METODE}

Bahan dan metode pelaksanaan kegiatan pengabdian ini kami laksanakan dengan rincian sebagai berikut:

\section{Metode Pelaksanaan}

Ruang lingkup kegiatan pelatihan mengenai penerapan Bea Perolehan Hak atas Tanah dan Bangunan (BPHTB) bagi penduduk desa antara lain:

1. Sosialisasi

peraturan perundangan:

a. Undang-Undang Republik Indonesia Nomor 20 Tahun 2000 Tentang Perubahan Atas UndangUndang Nomor 21 Tahun 1997 Tentang Bea Perolehan Hak Atas Tanah Dan Bangunan

b. Peraturan Direktur Jenderal Pajak Nomor PER-29/PJ/2009 Tentang Perubahan Kedua Atas Peraturan Direktur Jenderal Pajak Nomor 16/Pj./2005 Tentang Tata Cara Pemberian Pengurangan Bea 


\section{W/AHANA DEDIKASI}

Perolehan Hak Atas Tanah Dan Bangunan.

2. Bimbingan teknis mengenai:

a. Perhitungan BPHTB bagi Wajib Pajak Orang Pribadi atau Badan yang memperoleh hak atas tanag dan/atau bangunan di desa Kerinjing Kabupaten Ogan Ilir.

b. Cara pembayaran BPHTB bagi Wajib Pajak Orang Pribadi atau Badan yang memperoleh hak atas tanag dan/atau bangunan di Desa Kerinjing Kabupaten Ogan Ilir.

c. Pelaporan BPHTB bagi Wajib Pajak Orang Pribadi atau Badan yang memperoleh hak atas tanag dan/atau bangunan di desa Kerinjing Kabupaten Ogan Ilir.

\section{Bahan Kegiatan}

Adapun bahan kegiatan pelatihan mengenai penerapan $\mathrm{PPh}$ Pasal 21 bagi penduduk desa antara lain:

1. Perhitungan BPHTB bagi Wajib Pajak Orang Pribadi atau Badan yang memperoleh hak atas tanah dan/atau bangunan di Desa Kerinjing Kabupaten Ogan Ilir.

2. Cara pembayaran BPHTB bagi Wajib Pajak Orang Pribadi atau Badan yang memperoleh hak atas tanag dan/atau bangunan di Desa Kerinjing Kabupaten Ogan Ilir.

3. Penyusunan pelaporan mengenai BPHTB bagi Wajib Pajak Orang Pribadi atau Badan yang memperoleh hak atas tanag dan/atau bangunan di Desa Kerinjing Kabupaten Ogan Ilir.

$\begin{array}{ccc}\text { Pelatihan yang } & \text { diberikan } \\ \text { kepada } & \text { peserta } & \text { pelatihan }\end{array}$

menggunakan metode pembelajaran pedagogi. Metode ini memberikan pelatihan kepada peserta dimana peserta dianggap sebagai orang dewasa. Pembicara memberikan pelatihan dengan monolog kemudian dilanjutkan dengan cara dialog dua arah antara narasumber dengan peserta.

Pembelajaran monolog,
merupakan pembelajaran orang dewasa adalah dengan cara memberikan materi satu arah kepada peserta. Peserta memberikan arahan dari narasumber berbagai materi dan arahan teknis pengisian formulir. Pembelajaran monolog dilanjutkan dengan proses dialog. Proses dialog merupakan proses pemberian materi dan arahan kepada peserta dengan cara berdiskusi, bertatap muka dan curah pendapatan terhadap kasus dan materi serta berbagai arahan narasumber kepada perserta pelatihan.

Dalam proses pelatihan ini diusahakan memberikan beberapa contoh perhitungan berkaitan dengan

BPHTB bagi Wajib Pajak Orang Pribadi atau Badan yang memperoleh hak atas tanag dan/atau bangunan.

\section{HASIL DAN PEMBAHASAN}

\section{Proses Kegiatan Pelaksanaan Pengabdian}

Saat pelaksanaan pengabdian masyarakat di Desa Kerinjing kecamatan Tanjung Raja di Ogan Ilir, Sumatera Selatan, pertama pembukaan dari Kepala Desa Kerinjing yaitu bapak Faisal Kimi. Bapak kepala desa memberikan sambutan dengan pernyataan penerimaan atas kunjungan dosen- 


\section{W/AHANA DEDIKASI}

dosen Fakultas Ekonomi Unsri untuk melaksanakan pengabdian kepada masyarakat di desa Kerinjing. Masyarakat desa Kerinjing menerima dengan penuh rasa syukur untuk dapat memperoleh ilmu dan pengetahuan yang diberikan oleh dosen-dosen Fakultas Ekonomi Universitas Sriwijaya. Bapak kepala desa juga memberikan fasilitas yang diperlukan dalam rangka kegiatan pengabdian dan mengucapkan banyak terima kasih. Kata sambutan mewakili Dosen Fakultas Ekonomi Universitas Sriwijaya yang disampaikan oleh Bapak Dian Eka, SE, MSi., yang menjelaskan maksud dan tujuan serta manfaat kunjungan pengabdian kepada masyarakat di desa Kerinjing. Setelah pembukaan adalah doa bersama.

Kegiatan pelatihan dapat berjalan dengan lancar. Hal ini disebabkan adanya faktor yang mendukung berjalan kegiatan pengabdian. Hal-hal yang mendukung berjalannya kegiatan pengabdian ini yaitu adanya dukungan sepenuhnya dari masyarakat di Desa Kerinjing dengan menyediakan fasilitas tempat pelatihan dan menyambut baik adanya pelatihan ini dan harapan kedepan kegiatan pelatihan ini tetap dapat berlanjut di masa yang akan datang. Faktor pendukung yang lain adalah adanya antusiasme peserta untuk mengikuti pelatihan ini untuk memahami pentingnya BPHTB.

Pada saat sesi kami menyajikan pemaparan materi mengenai perhitungan dan pelaporan BPHTB kepada para aparat pemerintah desa Desa Kerinjing. Paparan difasilitasi oleh in fokus dan print out power point yang dibagikan kepada para peserta agar dapat memahami materi secara utuh. Paparan menyajikan materi dasar yaitu:

1. Pengertian Pajak

2. Fungsi Pajak

3. Pembagian Hukum Pajak

4. Pembagian Jenis Pajak

5. Tarif Pengenaan Pajak

6. Peraturan terkait pajak

Setelah itu disajikan materi khusus mengenai BPHTB, yaitu:

1. Pengertian BPHTB

2. Tarif Pengenaan BPHTB

3. Dasar Pengenaan BPHTB

4. Pemungutan BPHTB

5. Peraturan terkait BPHTB

Pada pelatihan ini, peserta juga diberikan contoh pencatatan dan perhitungan BPHTB. Selama ini mereka belum begitu memahami dan mengetahui tentang bagaimana cara membuat pencatatan keuangan yang benar secara akuntansi. Para peserta dapat mencoba untuk membuat pencatatan keuangan sesuai dengan penghasilan yang mereka terima dari usahanya serta mencoba untuk menghitung besarnya pajak yang harus dibayar dan membuat pelaporan pajak. Tim pengabdi memberikan bimbingan dan pendampingan secara langsung dalam membuat pencatatan keuangan, menghitung besarnya pajak yang harus dibayar berdasarkan dari penghasilan yang diterima dan membuat pelaporan pajak.

Di bawah ini disampaikan foto-foto kegiatan pengabdian kepada masyarakat sosialisasi pemahaman atas pajak bea perolehan hak atas 


\section{WAHANA DEDIKASI}

tanah dan bangunan (BPHTB) bagi masyarakat di desa kerijing.

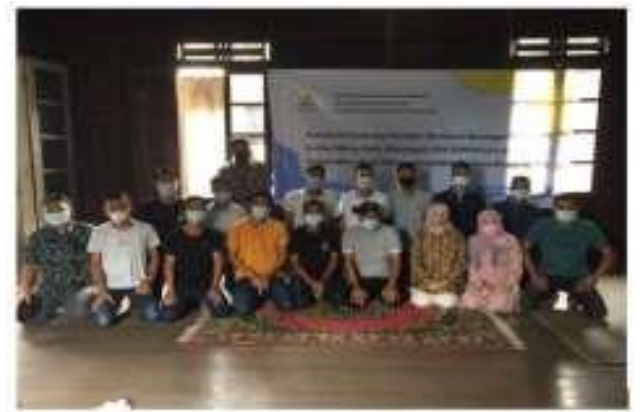

Gambar 1. Tim pengabdian bersama peserta pada saat pembukaan

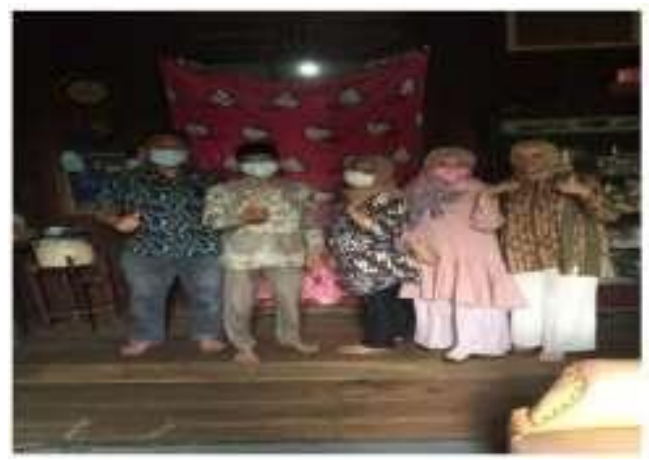

Gambar 2. Sambutan dari Kepala Desa Kerinjing

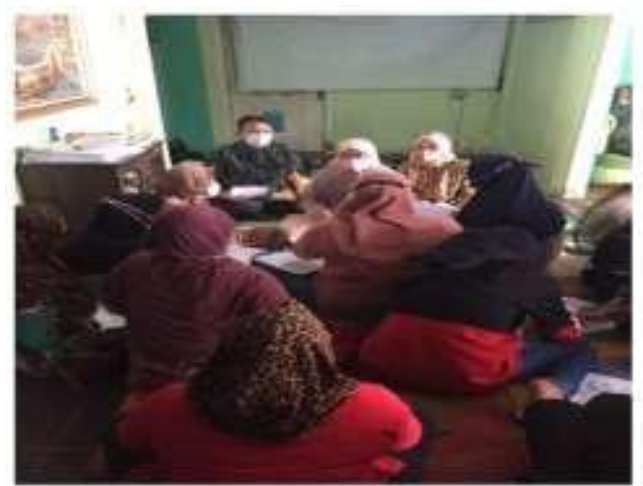

Gambar 3. Penyampaian Isi Materi Oleh Pemateri

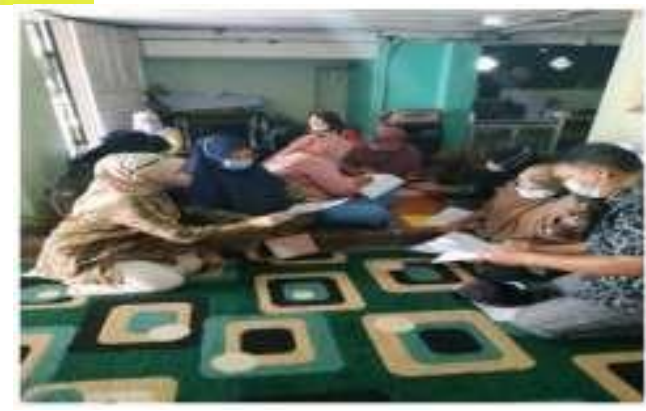

Gambar 4.Tim berdiskusi dengan peserta

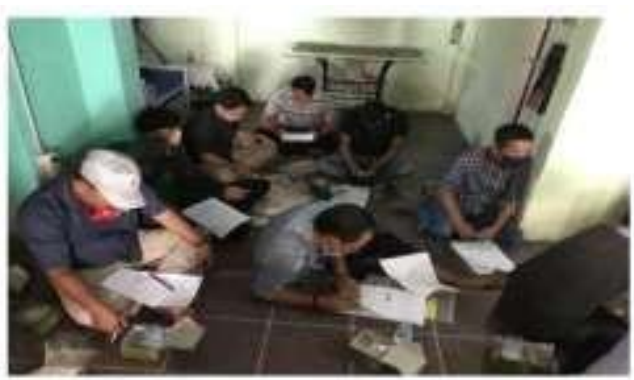

Gambar 5. Para Peserta Menyimak Isi Materi

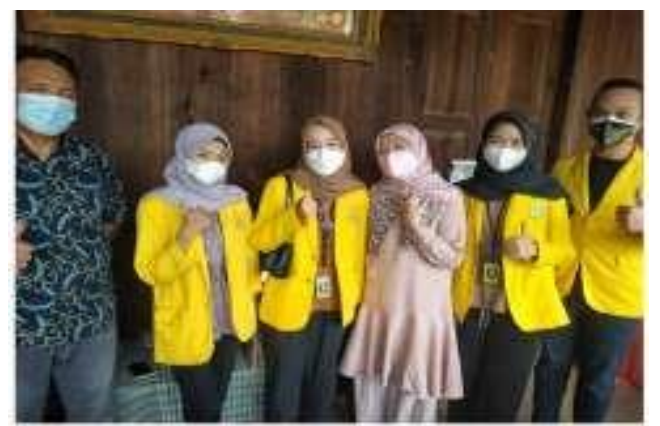

Gambar 6. Bersama mahasiswa yang terlibat dalam pengabdian

\section{KESIMPULAN}

Terdapat beberapa kesimpulan dari pengabdian ini yaitu sebagai berikut:

1. Peran aparat desa di Desa Kerinjing kecamatan Tanjung Raja Ogan Ilir berkaitan dengan BPHTB sangat besar.

2. Adanya kesesuaian materi pelatihan dengan kebutuhan 


\section{WAHANA DEDIKASI}

para aparat desa untuk meningkatkan pemahaman tentang BPHTB.

3. Adanya respon positif dilihat dari antusiasme para peserta pelatihan mengikuti kegiatan pengabdian.

4. Perlu adanya pendampingan bagi aparat desa dalam menghitung, memperhitungkan, membayar, melaporkan berkaitan dengan BPHTB. Terutama berkaitan dengan surat pemberitahuan (SPT) pajak baik SPT masa maupun tahunan

\section{DAFTAR PUSTAKA}

Fujihana, Y. (2010). Pengaruh Reformasi Pajak Dan Administrasi Perpajakan Modern Terhadap Kepatuhan Wajib Pajak (Survei pada KPP Pratama Kota Bandung di Kanwil DJP Jabar 1). Ekonomi, 1-25.

Ikatan Akuntan Indonesia. (2020). Modul Pelatihan Pajak Terapan Brevet $A B$ Terpadu. Jakarta: Ikatan Akuntan Indonesia.

Kementrian Keuangan Republik Indonesia. (2020). APBN KITA 2020.

Kertopati, P. (2015). Strategi Pemerintah DKI Jakarta Dalam Rangka Optimalisasi Penerimaan Bea Perolehan Hak Atas Tanah dan Bangunan (BPHTB). Perbanas Review, 1(November), 107-124.
Mauludiah, O. S. (2015). Efektivitas Self Asessment System Dalam Pemungutan Bea Perolehan Hak Atas Tanah dan Bangunan (BPHTBP. Universitas Brawijaya.

Peraturan Direktur Jenderal Pajak Nomor PER-29/PJ/2009 Perubahan Kedua Atas Peraturan Direktur Jenderal Pajak Nomor 16/Pj./2005 Tentang Tata Cara Pemberian Pengurangan Bea Perolehan Hak Atas Tanah Dan Bangunan.27 April 2009. Jakarta.

Prastikaningtyas, W., \& Permadi, I.

(2014).DASAR
KEBIJAKAN
PENGENAAN NILAI
PEROLEHAN OBYEK
PAJAK TIDAK KENA
PAJAK (NPOPTKP)
KARENA WARIS ATAS
TANAH YANG BELUM
BERSERTIPIKAT
(Analisa Pasal 100 Ayat 8
Peraturan Daerah
Kabupaten Malang
Nomor 8 Tahun 2010
tentang Pajak Daerah)
PAJAK TIDAK KENA
PAJAK (NPOPTKP )
KARENA WARIS ATAS (
Analisa Pasal 100 Ayat 8
Peraturan Daerah
Kabupaten Malang
Nomor 8 Tahun 2010
tentang PajakDaerah.

Resmi, S. (2017). Perpajakan (Kesepuluh; A. Sustiwi, Ed.). Jakarta: Salemba Empat. 


\section{WAHANA DEDIKASI}

Siahan, M. P. (2003). Bea Perolehan Hak Atas Tanah Dan Bangunan Teori dan Praktek. Jakarta: PT. Raja Grafindo.

Undang-Undang RI Nomor 20 Tahun 2000 Tentang Bea Perolehan Hak Atas Tanah Dan Bangunan. Jakarta. 